\title{
Oesophageal achalasia in adolescent women mistaken for anorexia nervosa
}

\author{
P D Duane, T M Magee, M S Alexander, R V Heatley, M S Losowsky
}

\section{Oesophageal} achalasia should be considered in adolescent women presenting with dysphagia even if other features suggest anorexia nervosa
Departments of Medicine and Psychiatry, St James's University Hospital, Leeds LS9 7TF

P D Duane, tutor in medicine M S Alexander, consultant psychiatrist

$\mathrm{R}$ V Heatley, senior lecturer in medicine

M S Losowsky, professor of medicine

High Royds Hospital, Menston, West Yorkshire

T M Magee, senior registrar in psychiatry

\section{Correspondence to:}

Dr P D Duane, department of medicine.

BMF 1992;305:43
Anorexia nervosa is a commonly considered diagnosis in young women who present with unexplained weight loss and vomiting. By contrast, achalasia is a rare disorder of the oesophagus and often goes unrecognised for many years. ${ }^{1}$ The main symptom of this condition is dysphagia, but regurgitation or vomiting of food and weight loss are also common. Occasionally patients with achalasia adopt abnormal eating habits, such as self induced vomiting and avoidance of food, which can be mistaken as behavioural features of anorexia nervosa. ${ }^{23}$ We present the case histories of two adolescent girls with achalasia who had eating disorders diagnosed after initial investigations failed to find a cause for their weight loss.

\section{Case histories}

\section{CASE 1}

A 17 year old schoolgirl had a one year history of dysphagia, which began soon after termination of an unwanted pregnancy. After six months she was regurgitating food to gain relief of her symptoms and was referred for a medical opinion. Apart from being somewhat thin $(45 \cdot 3 \mathrm{~kg}, 88 \%$ ideal weight $)$ she seemed healthy. She had menstrual periods but was taking an anovulant. A barium swallow examination showed some oesophageal dysmotility with intraoesophageal reflux. She was treated with domperidone, prochlorperazine, and cisapride without effect. The oesophagus and gastro-oesophageal junction appeared normal at endoscopy.

Over the next six months she lost $16.5 \mathrm{~kg}$ and was admitted to hospital twice after collapsing. Psychiatric assessment suggested an atypical eating disorder. She was transferred to St James's University Hospital for further psychiatric opinion. As she did not have the classic features of anorexia nervosa she was again investigated medically. Endoscopy showed some resistance to passage through the cardia. A barium swallow examination showed features typical of achalasia with absent peristalsis in the lower oesophagus and failure of relaxation of the gastrooesophageal junction. The results of oesophageal scintigraphy were consistent with achalasia with prolonged stasis and abnormal peristalsis. After pneumatic balloon dilatation (Rigiflex balloon) she had no difficulty in swallowing and was soon eating and drinking normally. Three weeks later she was asymptomatic and had put on $6 \cdot 2 \mathrm{~kg}$.

CASE 2

A 14 year old schoolgirl presented with a three month history of intermittent dysphagia. Her weight was $39.3 \mathrm{~kg}$ ( $80 \%$ ideal weight). She had no secondary sexual characteristics and had not started menstruating. Results of a barium swallow examination and endoscopy were reported as normal. Oesophageal scintigraphy showed oesophageal dysmotility with intraoesophageal reflux. When it emerged that she had been vomiting and hiding food for some time, anorexia nervosa was diagnosed and she was transferred to the care of à child psychiatrist.

Over the next nine months her dysphagia worsened and her weight dropped to $30.8 \mathrm{~kg}$. She was then transferred to St James's University Hospital for further medical assessment. A repeat barium swallow examination showed dilatation and absent peristalsis in the lower oesophagus, consistent with achalasia. She was treated with pneumatic balloon dilatation. Two years later her weight $(58.4 \mathrm{~kg})$ was normal for her height and age and she had normal menstruation and sexual development. She occasionally had dysphagic symptoms and required two further dilatations.

\section{Discussion}

Achalasia, characterised by absent peristalsis of the body of the oesophagus and inadequate relaxation of the lower oesophageal sphincter, has a reported annual incidence of 0.51 cases $/ 100000$ population in the Nottingham area.' Dysphagia is the initial and main clinical feature of this condition. Several years often elapse before the condition is diagnosed, by which time other symptoms such as vomiting and weight loss are common. Errors in diagnosis are related to delay in obtaining appropriate investigations or misinterpretation of their results. ${ }^{4}$

These two case histories show how achalasia can be mistakenly diagnosed as anorexia nervosa, particularly when the patient is emaciated, young, and female. Neither of these patients, in retrospect, had primary anorexia nervosa as they lacked the crucial features of this disorder - namely a distorted body image and fear of weight gain. It has recently been reported, however, that oesophageal motor disorders are common in patients meeting standard diagnostic criteria for primary anorexia nervosa. ${ }^{5}$ Seven out of the 30 patients in this study did, indeed, have achalasia. ${ }^{5}$ Moreover, behavioural features compatible with anorexia nervosa, such as wilful avoidance of food and spontaneous or self induced vomiting, have been reported in patients with achalasia and clearly can cause diagnostic confusion. ${ }^{23}$

Though psychiatric symptoms are common in patients with oesophageal contraction abnormalities, ${ }^{6}$ we recommend that dysphagia should be assumed to have a physical cause. Patients with dysphagia should have a barium swallow examination, preferably with video recording to study the dynamics of swallowing, before endoscopy, as endoscopy on its own can easily miss oesophageal motility disorders. If the complementary investigations of barium swallow and endoscopy are non-diagnostic, oesophageal manometry or scintigraphy, or both, should be done by experienced investigators.

\footnotetext{
Mayberry JF, Atkinson $M$. Studies of incidence and prevalence of achalasia in the Nottingham area. $Q f$ Med 1985;56:451-6.

Kenny RD. Achalasia in an adolescent with behavioral features compatible with anorexia nervosa. 7 Adoles Health Care 1984;5:283-5.

3 Stacher G, Wiesnagrotzki S, Kiss A. Symptoms of achalasia in young women mistaken as indicating primary anorexia nervosa. Dysphagia 1990;5:216-9. 4 Rosenzweig S, Traube M. The diagnosis and misdiagnosis of achalasia. A study of 25 consecutive patients. I Clin Gastroenterol 1989;11:147-53.

5 Stacher G, Kiss A, Wiesnagrotzki S, Bergmann H, Hobart J, Schneider C. Oesophageal and gastric motility disorders in patients categorised as having primary anorexia nervosa. Gut 1986;27:1120-6.

6 Clouse RE, Lustman PJ. Psychiatric illness and contraction abnormalities of the esophagus. N Engl f Med 1983;309:1337-42.

(Accepted 9 October 1991)
} 